\title{
Stratesy for oral rehabilitation concomitant to orthognathic surgery: implantoprosthetic treatment
}

\author{
S. Thévenot ${ }^{1}$, R. Carré ${ }^{1}$, Y. Lauverjat ${ }^{2}$
}

1 Dental surgeon

2 Senior lecturer, University of Bordeaux 2, Hospital practitioner, Clinical visiting professor, College of Dentistry, New York University, Physician in charge of the oral health unit,

CHU Bordeaux Pellegrin

\section{ABSTRACT}

New planning concepts can increase the predictability of overall treatment combining orthodontics, orthognatic surgery, and prosthetics. Issued from new computer and industrial technology, the process of guided maxillofacial surgery (simulation of orthodontic movements) and implant-prosthetic planning (prothetic projet and guided implant surgery) allow for indications to be expanded.

The digital stream, our communication tool, integrates the patient's overall aesthetic project, facilitates dialogue, pools therapeutic objectives by optimizing interdisciplinary protocol and determines a therapeutic schedule.

\section{KEYWORDS}

Planning, guided surgery, workflow, prosthetic rehabilitation, multidisciplinary treatment

\section{INTRODUCTION}

Achieving satisfactory results in the treatment of complex cases requires a multidisciplinary approach that allows the personal therapeutic limits of each party involved in the treatment plan to be extended.

Orthognathic surgery and implantology therefore allow us to overcome the challenges associated with orthodontics, such as loss of anchorage in cases of multiple edentulous spaces or restricted alveolar compensation, and of conventional prostheses, such as the impossibility of correcting gaps that are too large, midline shifts, open bite, overbite, or misalignment of the prosthetic axes. ${ }^{12}$ (Figure 1).

The objective of orthognathic surgery is to correct maxillomandibular deformities or dysmorphism, whether they are congenital or acquired. Comprehensive oral rehabilitation 


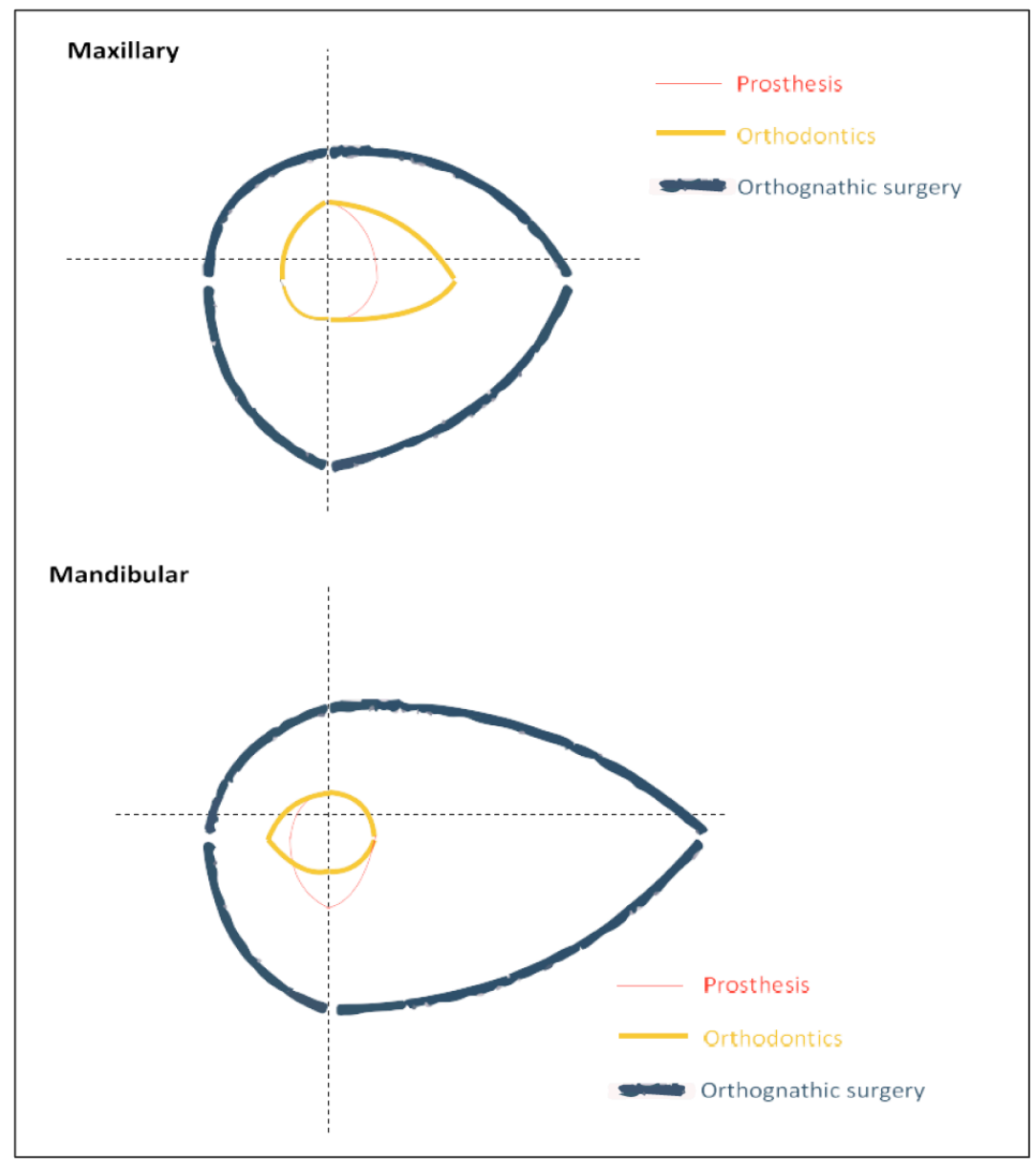

Figure 1

Diagram of the potential discrepancy according to each discipline (diagram modified according to Proffit and White's "envelope of discrepancy"21). The thickness of the lines indicates the precision of the displacement (the thinner the line, the more precise the displacement.)

serves to correct these alterations to achieve a harmonious dental morphology, smile, and facial appearance.

For obtaining stable results, the multidisciplinary alliance between orthodontist, dental implantologist, and maxillofacial surgeon must meet both the esthetic demands of the patient and respect requirements such as restoration of func- tional breathing, phonation, and mastication ${ }^{14}$.

The interplay of prostheses, periodontics, orthodontics, and surgery must be precisely defined and coordinated according to the therapeutic solution.

Digital workflow is the synergy of multidisciplinary work that allows for the simplification and improvement of the therapeutic protocol. 


\section{THERAPEUTIC PLANNING}

A treatment plan will be developed after periodontal sanitization and the elimination of any infectious sites, which can be a source of complications or even the cause orthognathic and implant surgery failure.

The first step, the diagnostic phase, involves the collection and pooling of different clinical data to create an ideal prosthetic plan.

\section{The Prosthetic Plan}

The prosthetic plan can be defined as the visualization of an optimal prosthetic rehabilitation protocol based on the retranscription of all the patient's clinical data ${ }^{16,1}$.

\section{Study Models}

Study models will be created from the original study impressions: either as a standard impression digitized in the prosthetics laboratory in the form of an open file (.stl) or as an optical impression. An acquisition system such as the 3Shape $\operatorname{TRIOS}^{\circledR}$ scanner, based on confocal technology, does not require any prior dusting and has a scanning precision of $20 \mu \mathrm{m}$. Images are recorded continuously with threedimensional reconstruction in color ${ }^{3}$.

Photographic images of the patient's face will be taken using a standard digital 2D or 3D camera. The aim is to create a morphing of the patient and to incorporate it into a Digital Smile De$\operatorname{sign}^{\circledR}$ (DSD) protocol or in the planning software for soft tissue management ${ }^{4,5}$.

\section{Development of a prosthetic plan $^{3,7,11,26}$}

Sending a patient's clinical data to the prosthetics laboratory on the basis of a simple plaster model is no longer sufficient for an esthetic reconstruction. Ascertaining the intermaxillary relationship and transferring this to an articulator with a facebow allows for the transmission of valuable occlusal information.

However, the mere communication of esthetic information is often insufficient. These data can be supplemented and transmitted to the laboratory with the aid of the Ditramax ${ }^{\circledR}$ system (Figures 2a, b, c).

This system allows esthetic reference lines of the face to be recorded and transferred onto the plaster model, thereby facilitating the creation of prostheses. This tool can also be used throughout the diagnostic phase when developing the prosthetic project, when creating temporary teeth, or even in the final phase of development of custom prostheses.

Ditramax simplifies the job of the prosthetist by using photographic data (age, sex, facial type) and occlusal data of the patient, and allows the number of trial sessions necessary to correct the shapes and axes of the prosthetic teeth to be decreased. This optimizes esthetic integration of future prostheses ${ }^{15}$.

Using a wax-up, the prosthetist redefines the occlusal curves and the anterior region to achieve harmony 


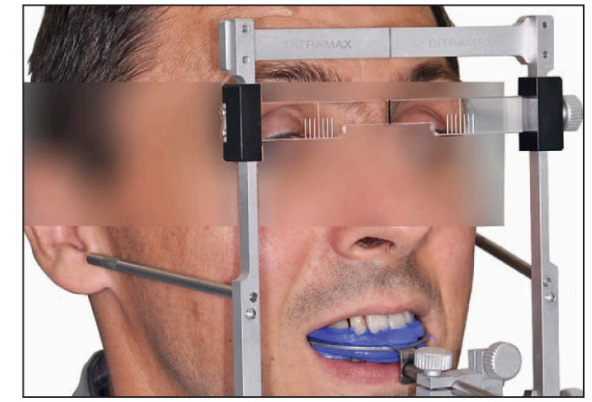

(a)

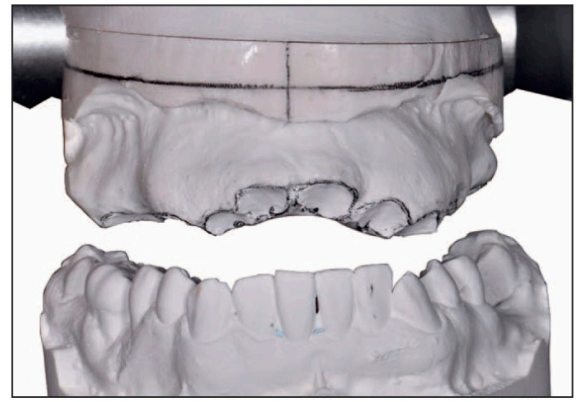

(b)

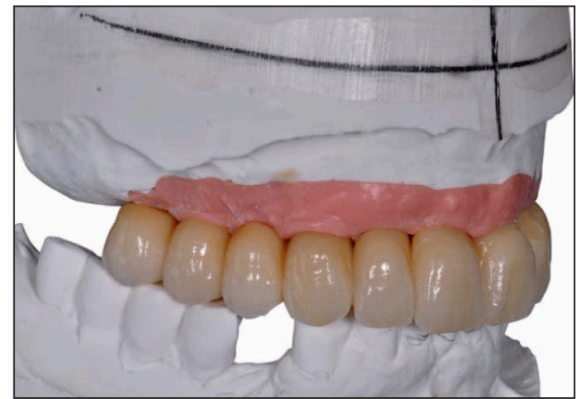

(c)

Figure 2:

(a) Recording of esthetic reference lines using Ditramax ${ }^{\circledR}$; (b) Transfer of data from Ditramax ${ }^{\circledR}$ to plaster models; (c) Creation of a custom ceramic bridge (Dr. Patrice Margossian).

with the gingiva, lips, and face of the patient. Mandibular kinematics can be simulated by means of a virtual articulator managed by the CEREC software version $4.2^{25}$.

In the 3D planning software, the model of the wax- up will be scanned (*.stl format) and subsequently "matched" with the radiological files and/or photographs.

\section{Radiological examination ${ }^{27}$}

Tomodensitometry (or X-ray scanning) and cone-beam computed tomography (CBCT) are two types of $\mathrm{X}$-ray imaging that offer three-dimensional reconstructions.

CBCT will henceforth be used in dentomaxillary imaging for the following reasons:

- Its introduction to dental offices;

- It offers acquisition fields of $5 \times 5$ (small field) up to $12 \times 12$ (large field) depending on the examination;

- A considerably smaller irrigation dose in comparison with a scanner;

- Better-quality images thanks to the reduction in artifacts.

The image obtained is converted to a Digital Imaging and Commu- nications in Medicine (DICOM) file $(. \mathrm{dcm})$, which is an open file format that can be used by all implant and maxillofacial surgery planning software platforms.

\section{CBCT allows for ${ }^{2,23}$}

- Morphological and diagnostic analysis of dental elements;

- Analysis of the anatomical relationships between the teeth and their surrounding structures. Notably the position of the mandibular canal, the protrusion of the mental foramen, the positions of the descending palatal and anterior alveolar arteries, the floor of the nasal cavity and the volumes of the sinuses;

- Analysis of anatomical osseous and articular structures and of air cavities.

\section{Data matching}

Data matching involves the practitioner matching the radiological images with the patient's dental models in the prosthetics laboratory to create a single 3D file. This is achieved by "matching," which involves linking strategic points. This file, integrated 


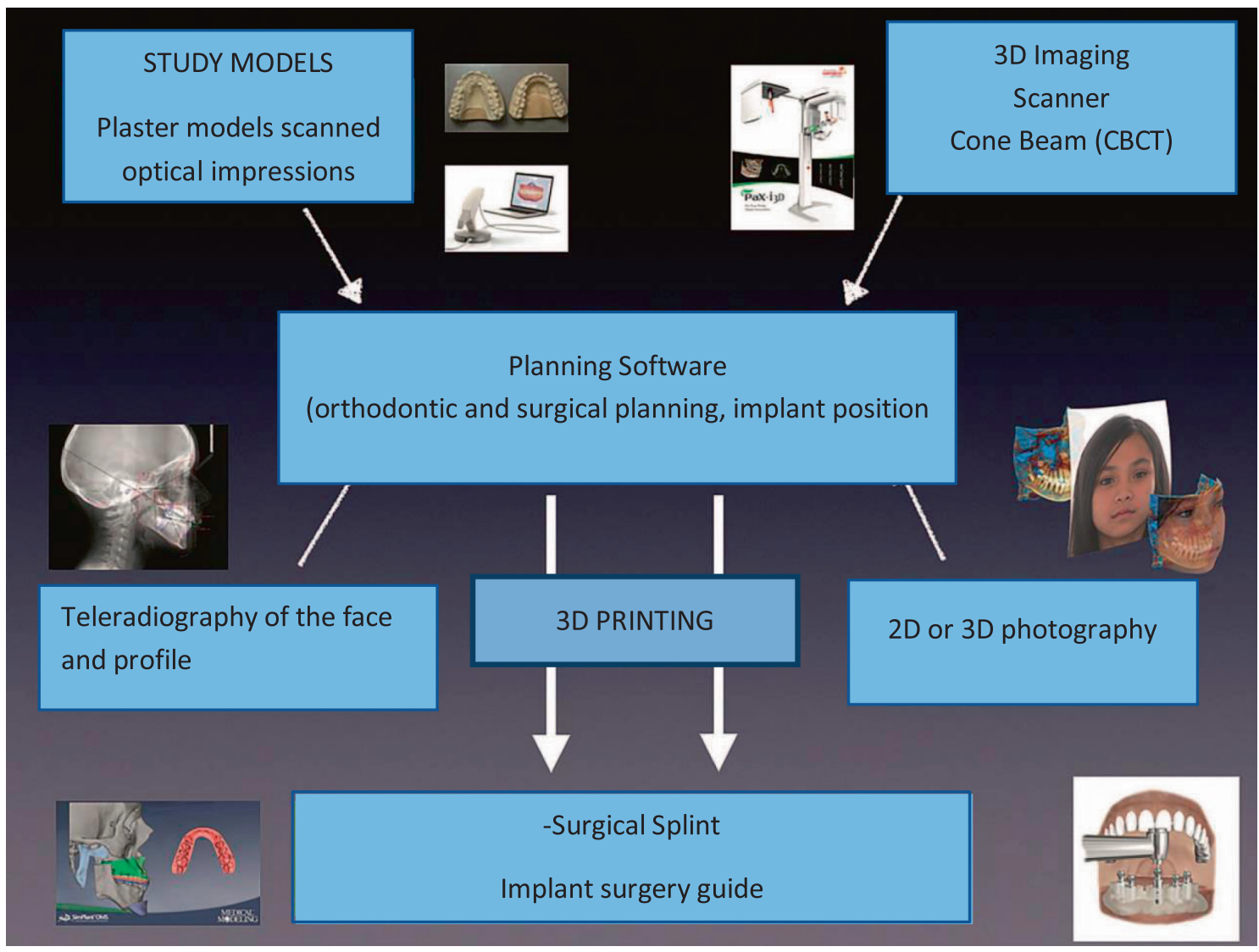

Figure 3

Integration protocol for clinical data for the purpose of planning.

in 3D planning software, will allow each player in the treatment plan to work in collaboration (Figure 3).

\section{D simulation ${ }^{20}$}

Planning software has been developed for each discipline; however, we will be focusing on multidisciplinary software programs (Invivo $5^{\circledR}$ by Anatomage Dental, SimPlant $\mathrm{OMS}^{\circledR}$ by Materialise Dental, Maxilim $\AA$ by Medicin, and Dolphin 3D ${ }^{\circledR}$ from Dolphin Imaging).

These software programs are capable of (Figures 4, 5):

- Cephalometric analysis in 2D and 3D with integration of telera- diographs of the face and profile (Figure 6);

- Calculation of angles, lengths, and bone densities in Hounsfield units;

$-3 D$ analysis of airways before and after simulations;

- Highlighting and marking of anatomical elements such as the mandibular nerve, protrusion of the mental foramen, descending palatal artery, sinus, etc.;

- Segmentation of different parts (sinus, maxillary airways, mandible, virtual extractions);

- Simulation of tooth displacement (integration of the orthodontic setup); 

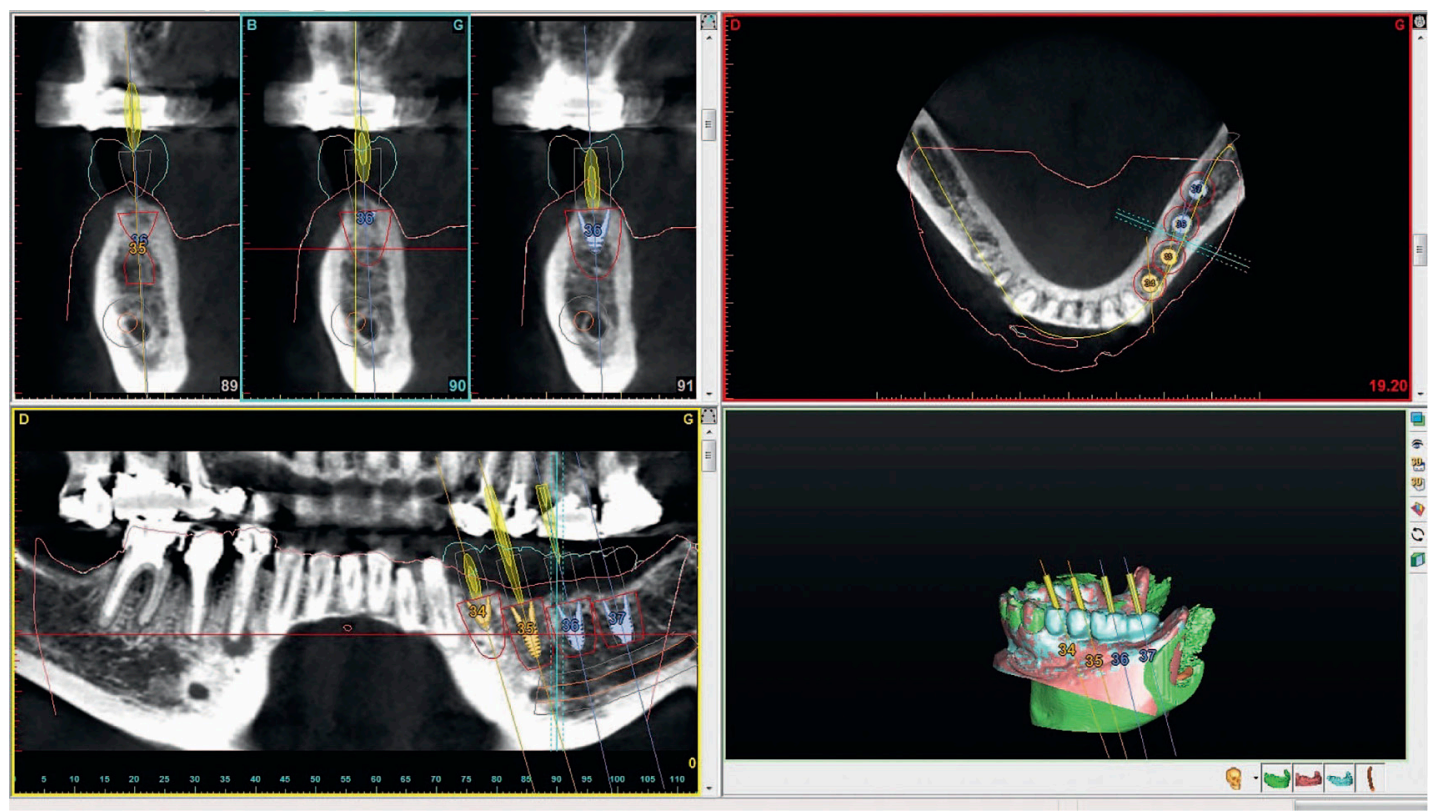

Figure 4

Implant planning using 3D reconstruction software (SimPlant $\left.{ }^{\circledR}\right)$.

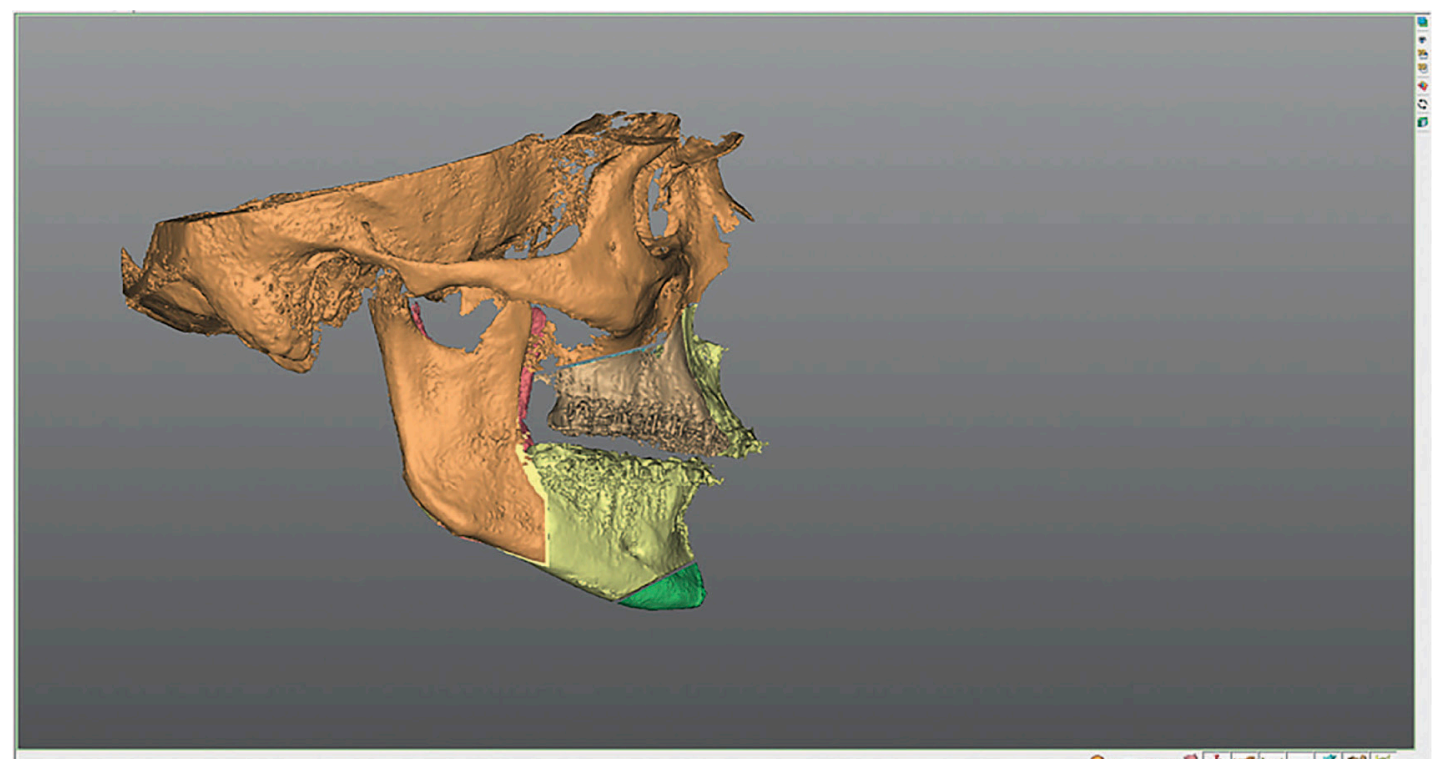

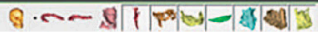

Figure 5

Simulation of osteotomies and osseous displacement (SimPlant OMS). 
- Simulation of osteotomies of osseous bases (LeFort 1, bimandibular osteotomies, genioplasty);

- Integration of photographs of the patient's face for simulation of the facial envelope with esthetic rendition of postoperative modifications;

- Placement of implants with their columns in 3D;
- Designing of surgical guides to facilitate implant placement via guided surgery (Figure 7);

- Designing of osteotomy guides for maxillofacial osteotomies;

- Designing of supportive mini-plates for surgery, prefabricated according to the patient's anatomy and the degree of displacement;

- Simulation of bone grafts ${ }^{18}$.

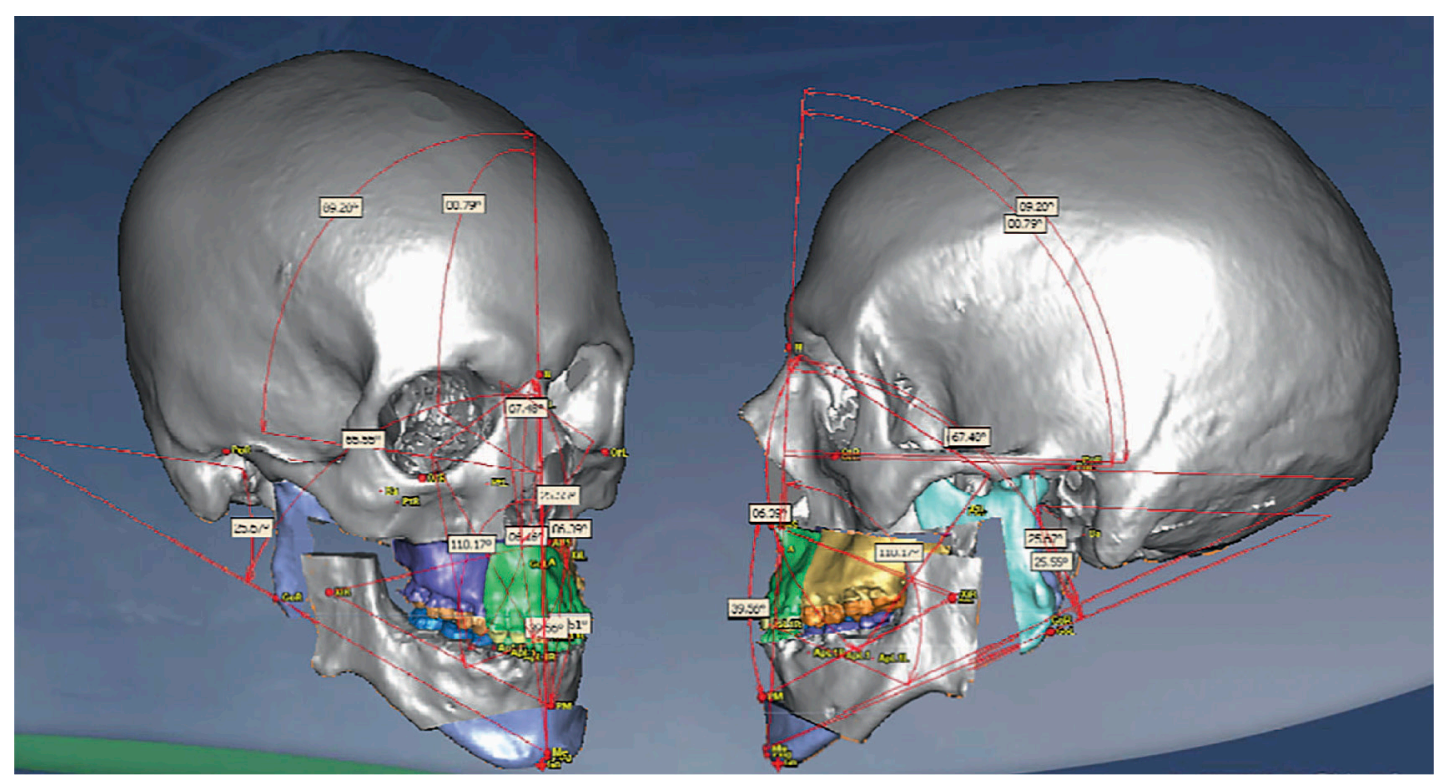

Figure 6

Cephalometric analysis and simulation of osteotomies using SimPlant OMS ${ }^{\circledR}$.

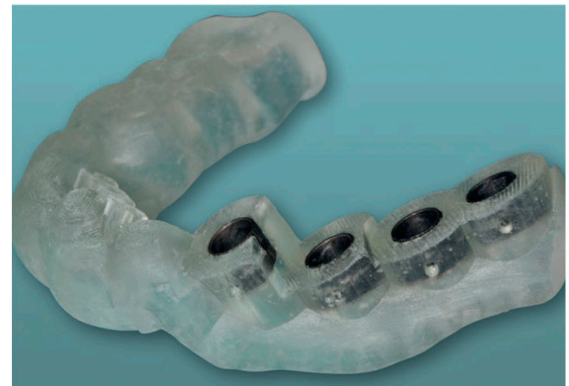

(a)

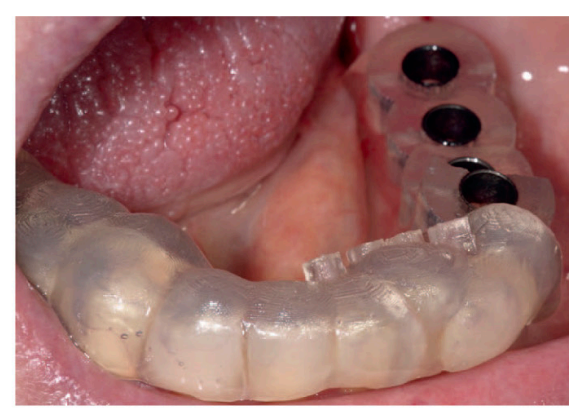

(b)

Figure 7

Stereolithographic guide for implant surgery (SimPlant $\left.{ }^{\circledR}\right)(a, b)$. 


\section{THERAPEUTIC APPLICATION AND THE SURGICAL PHASE}

\section{Cases of single or multiple edentulous spaces}

The objective is to propose an alternative to orthodontics/orthognathic surgery with placement of "conventional" implants to optimize the therapeutic timeline with outcomes that are in alignment with our expectations.

\section{Before orthodontic treatment}

Adult patients seeking comprehensive treatment often present with one or more edentulous spaces of moderate or large size, and most commonly located in the back of the mouth.

Guided implant placement using prosthetics prior to orthodontic treatment allows us to:

- Resolve loss of anchorage by avoiding the placement of temporary anchorage elements such as miniscrews or orthodontic anchorage plates;

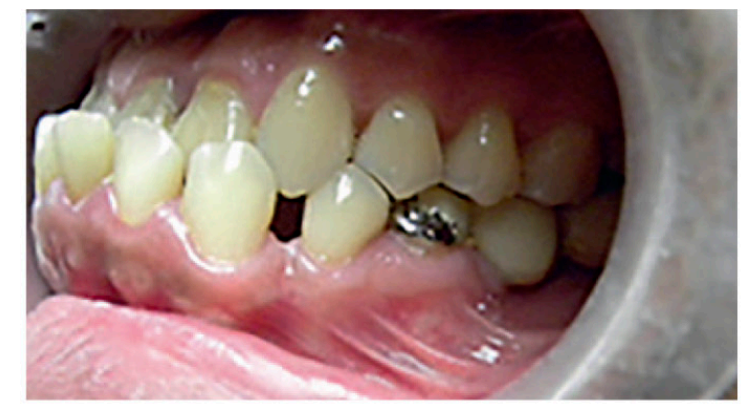

(a)

\section{(b)}

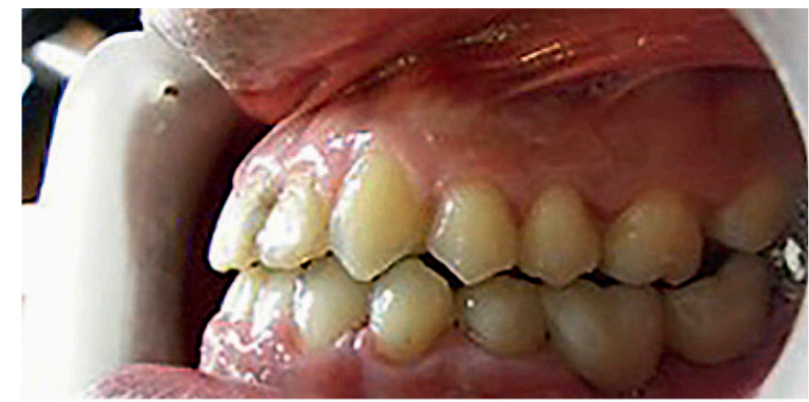

Figure 8

(a) Initial status; (b) Result of orthognathic surgery, orthodontic treatment, and prosthetic rehabilitation (Dr. Makaremi Masrour).
- Enhance the efficiency of the orthodontic treatment;

- Obtain provisional data on the implants after 6 weeks of osseointegration and to accelerate the creation of custom crowns ${ }^{9}$.

\section{During orthodontic treatment}

This protocol will help to decrease the number of surgeries the patient must undergo. The placement of dental implants will be integrated into the standard protocol of orthodontic treatment and orthognathic surgery. The implants will be placed on the day of orthognathic surgery with the aid of a surgical guide (pilot guide or full-guided) $)^{17,22}$.

With this method, the orthodontist does not have to use the implants for anchorage. The fitting of custom crowns will be done according to the traditional process (Figure 8) depending on the progress of the orthodontic treatment and the time needed for osseointegration (3-6 months) ${ }^{8}$. 
With the ageing of populations worldwide, prioritization will be given to those patients who already have implants that could complicate planned treatments. The poor positioning of implants could compromise the orthodontic process, orthognathic surgery, and consequently the prosthetic treatment ${ }^{24}$.

Removal of implants is often associated with significant damage to the alveolar bone. An alternative to implant removal is the repositioning of implants by means of segmental osteotomy during orthognathic surgery. The implants are then supported with a temporary metallic bridge, which acts as a brace to stabilize the osteotomy. The option of repositioning the implants allows surgical removal, which involves significant bone loss, to be avoided, thus eliminating the need for surgical intervention to reconstruct the bone and the surrounding soft tissue ${ }^{13}$.

\section{Cases of complete unimaxillary edentulism ${ }^{6,19}$ (Figures 9, 10, 11)}

The benefit of concomitant treatments in these cases is to decrease the number of surgeries for the patient and to decrease amount of time spent on comprehensive treatment.

The maxillofacial surgeon and orthodontist will use 3D planning software to determine in advance where the implants will be placed.

A decision will be made to manufacture several stereolithographic guides.

The first guide will be used to reposition bone segments and will allow the maxillofacial surgeon to optimize the displacement of osseous bases. A second guide will enable us to perform guided implant surgery. Eventually, the maxillofacial surgeon will be able to design osteotomy guides.

Full arch treatment, with or without extraction on the day of implant

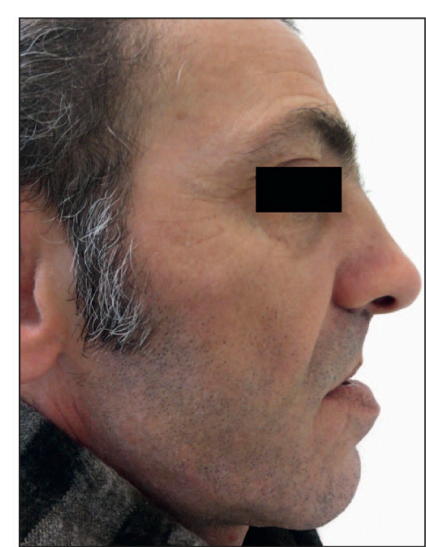

(a)

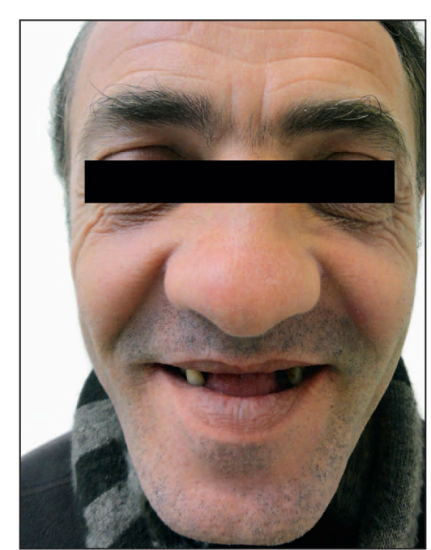

(b)

Figure 9

Initial status of the face and profile $(a, b)$. 

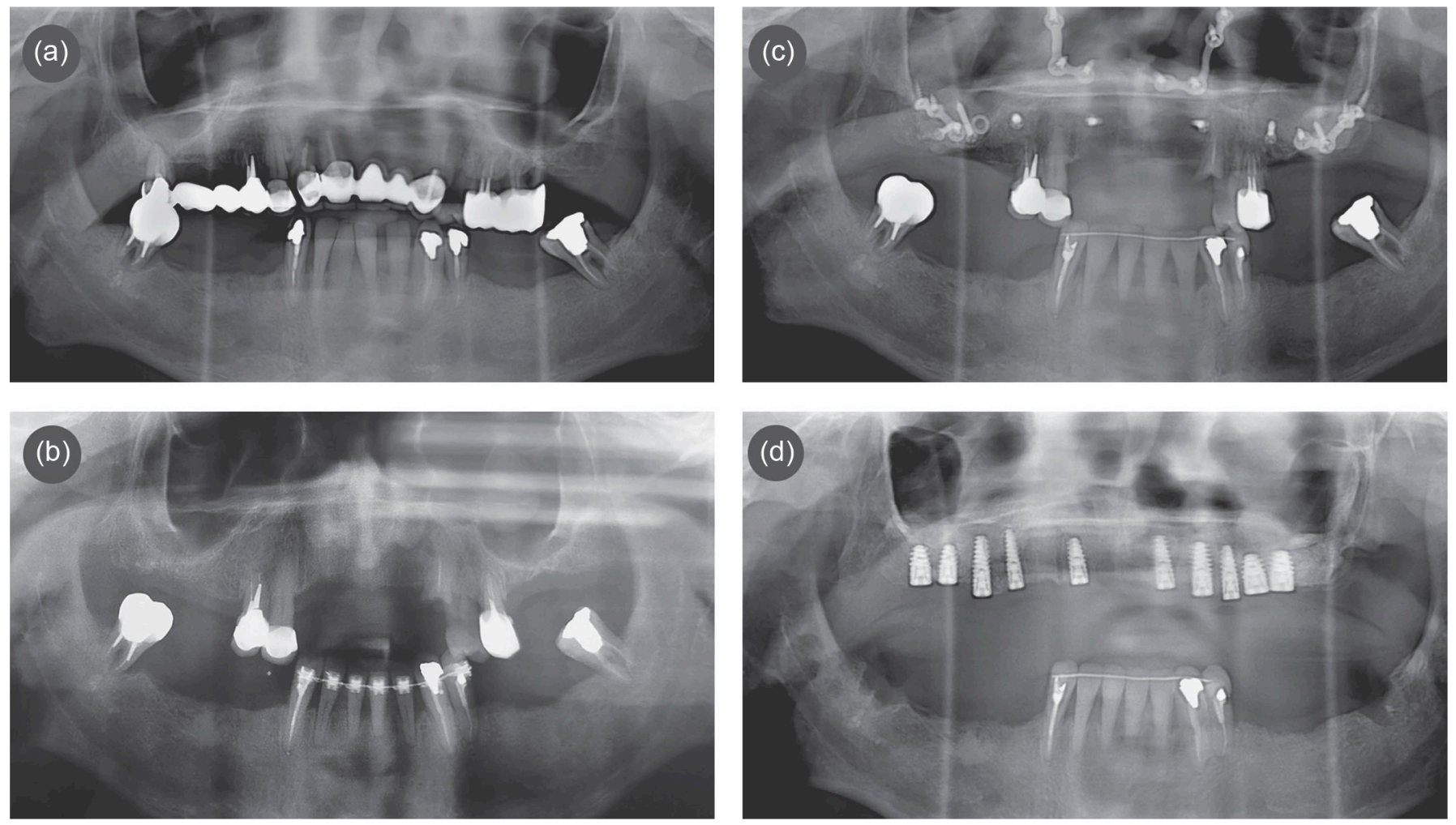

Figure 10

Panoramic dental radiographs at the different stages of treatment: (a) Initial status; (b) After the first sanitization and orthodontic intervention (Dr. Cédric Bazert); (c) and (d): After orthognathic surgery and the placement of implants (Dr. Mohamed El Okeily).

placement, will allow us to perform immediate esthetic treatment on the same day.

A resin bridge reinforced with a metal frame will be prepared beforehand in the prosthetics laboratory for potential mounting to the implants, after taking an impression of the positioning of fixtures or by relining the mouth and inserting the bridge within 24-48 h of surgery.

A temporary bridge mounted on the implants allows for intermaxillary ligation in cases of complete edentulism.

After 6 months of osseointegration, the temporary bridge will be removed and replaced with a custom bridge that is fixed on a titanium rod or zirconia frame with a tooth mounting made from a resin porcelain veneer.

\section{Monitoring of usage and maintenance ${ }^{10}$}

Prosthetic and implant maintenance is defined as the sum of all necessary measures to prevent complications or secondary failures and to ensure the long-term survival of implants. 


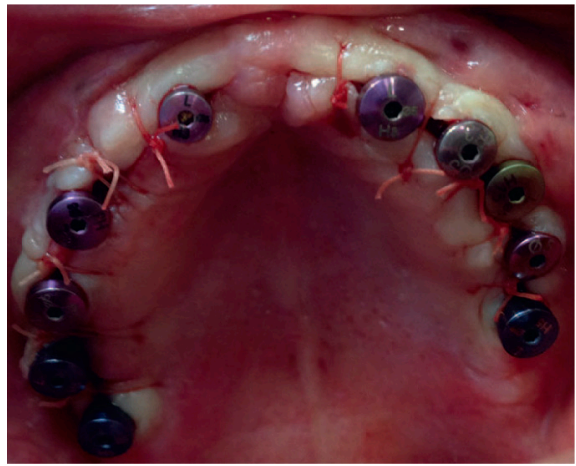

Figure 11

Postoperative intrabuccal view after maxillary implantation: note the repositioning of the keratinized tissue around the implant vestibules (surgery by Dr. Mohamed El Okeily).

Maintenance will begin after the placement of the custom prosthesis.

During the first year of use, it is advised to follow up the patient every 3-4 months to monitor the inflammatory state of the peri-implant and occlusive tissues. At the end of the first year, retro-alveolar radiographs will be taken to monitor any potential peri-implant bone loss. The periimplant survey will only be conduct-

\section{CONCLUSIONS}

Computer-aided design and Computer-aided manufacturing have helped usher in a major evolution in our profession; a turning point in the application of comprehensive rehabilitation.

Digital workflow is applied at every stage of our plan, including the diagnostic imaging, intraoperative, and prosthetic restoration phases. The consolidation of digital datasets in implantology has allowed for massive progress in the diagnosis and treat- ed in cases of inflammation with low pressure $(<20 \mathrm{mg}$ ).

Over the course of the second year, the frequency of maintenance visits must be determined based on the presence of risk factors with a special program tailored to the patient's profile (such as general health, smoking habit), the type and extent of the edentulism treated, the presence of parafunction or dysfunction, and the state of the remaining teeth.

In patients with a history of periodontitis or peri-implantitis, quarterly visits should be scheduled.

Biannual visits over 2 years will be sufficient for patients without any medical history and will become annual after the first 2 years. Implant maintenance requires the use of curettes (preferably in titanium) to sanitize the implant and peri-implant tissues, and an ultrasonic scaler fitted with titanium inserts or an air polisher that has a "perio-flow" nozzle so-named because of its "perio" powder.

ment of our patients. The precision of the radiological images, scanners, and optical scanners allows for more rigorous planning, thereby optimizing implant positioning while respecting bone volumes. This should improve the predictability of the treatment and help to achieve optimal integration of prosthetic restorations.

The current issue of population aging is causing an increase in the number of candidates seeking to correct 
dentofacial defects. The growing demand from our patients has been communicated and emphasized by the different media, which forces us to optimize our method of work- ing and to develop new protocols to better respond to these demands in terms of esthetics and treatment duration.

\section{ACKNOWLEDGMENTS}

The authors would particularly like to thank:

Dr. Mohamed El Okeily

Dr. Makaremi Masrour

Dr. Philippe Chanel

Dr. Cédric Bazert

Dr. Patrice Marghossian

Conflict of Interest: The authors declare no

conflicts of interest.

\section{BIBLIOGRAPHY}

1. Cannas $B$, Boutin $N$, Tran. Le flux numérique en implantologie, application à la mise en charge et, ou à I 'esthétique immédiate. Implant 2014;20:95-103.

2. Cazevian R, Pasquet G. Imagerie cone beam et implants. Rev Stomatol Chir Maxillofac 2012;113:245-258.

3. Cazier S, Moussaly C. Descriptif des différents systèmes d'empreinte optique. Rev Odont Stomat 2013;42:107-118.

4. Cordelette M. Le protocole esthétique en CFAO. Dentoscope 4/2014.

5. Crescenzo H. et al. Le projet virtuel: comment retrouver l'esthétique et l'occlusion? ID 25 février 2015;8:1415.

6. Dada K. Planification et chirurgie implantaire chez l'édenté complet. Réalités Cliniques 2013;24:17-36.

7. Davarpanah $\mathrm{K}$, et al. Nouveau protocole de planification 3D, integrated digital workflow. ID 24 septembre 2014;96:12-18.

8. Davarpanah M, Szmulker-Moncler S, Rajzbaum Ph, Davarpanah K, Demurashvili G. Manuel d'implantologie clinique: concept, intégration des protocoles et esquisses de nouveaux paradigmes. 3 éd. RueilMalmaison: JPIO Éditions CDP 2012:573-631.

9. Davarphanah K, Dreyfus-Schmidt E, SzmuklerMoncler S. Protocole ortho-implantaire dans le traitement de la dysharmonie dento-faciale chez l'adulte partiellement édenté. Titane 2014;11:263-271.

10. Giovannoli J-L, Renvert S. Péri-implantites. Paris: Quintessence international, 2012: 236-247. 
11. Greven M. Reconstruction implanto-portée antéposition et dimension verticale d'occlusion. Réalités cliniques 2013;24:147-152.

12. Joseph G. Apport de I'orthodontie au traitement pluridisciplinaire du sourire. Implant revues (cahiers de prothèse) Mai 2015. "L'esthétique du sourire: au cœur de toutes les spécialités".

13. Kassolis JD, Baer ML, Reynolds MA. The segmental osteotomy in the management of malposed implants: a case report and literature review. J Periodontol 2003;74:529-536.

14. Mantout B, Blanc JL. Simulation de modifications chirurgicales de la DVO. Réalités cliniques 2013;24:153-158.

15. Margossian P, et al. Communication des données esthétiques faciales au laboratoire: le système Ditramax ${ }^{\circledast}$. Réalités Cliniques 2010;21:149-155.

16. Paris JC, Faucher A. Le guide esthétique, comment réussir le sourire de vos patients. Paris: Quintessence international, 2004:1-309.

17. Park JY, Ahn KM, Lee JH, Cha HS. Full mouth rehabilitation on a bilateral condylar fractured patient using orthognathic surgery and dental implant. J Adv Prosthodont 2011;3:51-55.

18. Philippe B. Chirurgie orthognatique guidée. Id 2015;26:14-21.

19. Pompignoli $M$. Le projet prothétique préalable à la prothèse implantaire. Réalités cliniques 2013;24:5-16.

20. Popat H, Richmond S, Drage NA. New developments in: three-dimensional planning for orthognathic surgery. J Orthod 2010;37:62-71.

21. Proffit WR, White RP Jr. Surgical-orthodontic treatement. St Louis: Mosby Year Book, 1992:493 p.

22. Ritto FG, Medeiros PJ, de Oliveira Mussel RL, de-Sá- Silva E. Rehabilitation of an adolescent with ectodermal dysplasia. Two-stage orthognathic, graft, and implant surgery: case report. Implant Dent 2009;18:311-315.

23. Salmon B, Martinez H. Applications cliniques de l'imagerie en chirurgie orale: modalités et indications. Réalités cliniques 2014;25:155-166.

24. Ohba $S$, et al. Oral rehabilitation with orthognatic surgery after dental implant placement for class III malocclusion with skeletal asymmetry and posterior bite collapse. Implant Dent 2015;24:487-490.

25. Shivamurthy S, Nandeesshwar DB, Saritha MK. Virtual Articulators: a future oriented technology. Review article. Asian J Med Cli Sci 2012;1:98-101.

26. Slavicek R, Pedinielli A, Orthlieb JD. Typologie squelettique et choix de la dimension verticale d'occlusion. Réalités cliniques 2013;24:119-125.

27. Vallaeys K, Hodez C. Imagerie dentomaxillaire par faisceau conique: principes, matériels, indications et dosimétrie. Réalités cliniques 2014:25:103-114. 